\title{
The Sputtering of Target by Charged Particles and Energy Spectra of Sputtered Atoms
}

https://doi.org/10.32792/utq/utj/vol11/2/6

\author{
Sanaa Thamer Kadhum ${ }^{1}$, Saher Mezher Mutasher ${ }^{2}$ \\ ${ }^{1}$ Department of , College of Medicine, Thi-Qar University \\ Physics \\ ${ }^{1}$ E. mail: sanathamir @ yahoo com \\ ${ }^{2}$ Department of , College of Medicine, Thi-Qar University \\ Physics \\ ${ }^{2}$ E. mail: saheralasdi @ yahoo com
}

\begin{abstract}
:
In this paper, we introduce a study of understanding the physical sputtering of target by energetic ions bombardment as a result from cascades of linear collisions. There are two stages of collision cascade: high energy collisions which Thomas - Fermi cross section is applied and low energy collisions that Born - Mayer cross section is characterized. The sputtering may be divided into two parts sputtering potential and sputtering yield. In this paper, we emphasize on sputtering yield which is evaluated under the slowing down of energetic ions in a medium. The resulted yield equation is extended from Boltzmann transport equation. The resulted sputtering yield of $\mathrm{Ag}, \mathrm{Cu}$ and $\mathrm{Pd}$ targets has been measured with different incident ions. There is a variation in the yield with projectile atomic number and a deviation in the maximum of energy is found for both heavy and light projectiles. Also, we also study a formula proposed by Thompson to describe the energy spectrum of atoms sputtered from a target material irradiated by heavy ions and this formula may be expressed in terms of a normalized energy distribution function. A program in matlab is written in order to program the equations and obtain the results.
\end{abstract}

Keywords: sputtering, sputtering yield, collision cascade, Thomas - Fermi interaction, Born- Mayer interaction, energy spectrum.

\section{Introduction}




\section{University of Thi-Qar Journal Vol.11 No.2 June 2016}

Web Site: https://jutq.utq.edu.iq/index.php/main Email: journal@jutq.utq.edu.iq

Sputtering is the erosion of material by single - particle impact[1]. Sputtering occurs when displaced atoms in the near surface region have enough energy to escape from the surface. This type of sputtering is called physical or knock - on sputtering, as opposed to chemical sputtering which involves a chemical reaction[2]. The elastic sputtering is induced by the momentum transfer from the primary particle to the target atoms.

In recent years, many results of experiments concerning with sputtering by energetic bombardment have been collected. Most experiments dealt with measurements of the sputtering yield versus energy for many ion - target combinations, but a great amount of work has been done in investigating the angular and energy distribution of sputtered particles, or their average energy. Sputtering experiments concern with amorphous targets, polycrystals of diverse degrees of texture, and single crystals[3].

In the last fifteen years, theoretical efforts are increasingly successful in understanding the main features of sputtering in terms of a series of quasi elastic collision processes induced by the bombarding ion. Although the sputtering process is a common feature which governs the concept of a collision cascade in all recent sputtering theories, there are substantial differences in the main processes that various authors consider responsible for sputtering[3].

Advanced theories of energy loss of heavy particles in matter through Lindhard et al. work [4] and the theory of sputtering by Sigmund have much stimulated this growth[3]. Sigmund's analytical theory is the standard theory for sputtering which is based on Boltzmann transport theory. The obtained solution is in the limit of high primary energy compared to the instantaneous energy of the cascade atoms[3,5].

Lindhard et al. [6] established cross sections governing collisions of ions and atoms in $\mathrm{KeV}$ from Thomas - Fermi theory and showed that one can predict ions ranges exactly by using these cross sections[4]. Sanders[7] generalized Lindhard's procedure to calculate the spatial extension of a collision cascade and the momentum distribution of recoiling atoms based on the Thomas-Fermi scattering cross section[6] and assumed that all collisions are elastic.

In Thompson formula for the energy distribution function of atoms sputtered, it supposes that sputtered atoms originate in a well - developed collision cascade created only by heavy ions in a material [8]. However, an 
experiment shows that the energy spectrum due to low-energy light ions differs from that calculated with the formula. This deviation can be understood from the fact that light ions cannot produce such a cascade, but rather a single or multiple collision sequence[9].

\section{The Theoretical side}

\subsection{Slowing - down of Charged Particles in a Solid}

The stopping force $(\mathrm{dE} / \mathrm{dx})$ can be defined as the force which the medium exerts on the penetrating particle[10]:

$\mathrm{dE} / \mathrm{dx}=\mathrm{NS}(\mathrm{E})$

where $\mathrm{N}$ is the number density of atoms in the medium and $\mathrm{S}(\mathrm{E})$ is the stopping cross section which depends on the kinetic energy $\mathrm{E}$ of the primary particle. The collisions between the primary ions and the atoms in a solid can be divided into collisions between the primary particle and the nuclei and those between the primary and the electrons. $S(E)$ can be split up into[10] $\mathrm{S}(\mathrm{E})=\mathrm{S}_{\mathrm{n}}(\mathrm{E})+\mathrm{S}_{\mathrm{e}}(\mathrm{E})$

$\int_{0}^{\mathrm{T}_{\mathrm{m}}} \mathrm{Td} \sigma(\mathrm{E}, \mathrm{T})$ $\mathrm{S}_{\mathrm{n}}(\mathrm{E})=$ $\mathrm{T}_{\mathrm{m}}=\gamma \mathrm{E}$

$\gamma=4 \mathrm{M}_{1} \mathrm{M}_{2} /\left(\mathrm{M}_{1}+\mathrm{M}_{2}\right)^{2}$

where $S_{n}(E)$ is the nuclear stopping cross section, $S_{e}(E)$ is the electronic stopping cross section , $\mathrm{d} \sigma$ is the interaction cross section, $\mathrm{T}$ is the transferred energy (or recoil energy), $\mathrm{T}_{\mathrm{m}}$ is maximum value of $\mathrm{T}$ achieved in a head on collision, $\gamma$ is sputtering efficiency which turned out to be independent of ion energy for a given power cross section and is also insensitive to $m, M_{1}$ is the mass of ion, $M_{2}$ is the mass of target atom and $E$ is the energy of the impinging particle.

\subsection{Cross Section for Elastic Scattering}

Elastic collisions are characterized by an atomic potential, which may be written in the form[11] 


\section{University of Thi-Qar Journal Vol.11 No.2 June 2016}

Web Site: https://jutq.utq.edu.iq/index.php/main Email: journal@jutq.utq.edu.iq

$\mathrm{V}(\mathrm{r})=\frac{\mathrm{z}_{1} \mathrm{z}_{2}}{\mathrm{r}} \Phi\left(\frac{\mathrm{r}}{\mathrm{a}_{12}}\right)$

(6)

where $r$ is internuclear distance, $\Phi$ is a universal screening function most often independent of $\mathrm{Z}_{1}$ and $\mathrm{Z}_{2}$ (atomic number of the incident ion and target atom), and $\mathrm{a}_{12}$ is a screening radius for the collision partners. Any dependence on charge states is usually neglected.

$\Phi(\xi)=\mathrm{e}^{-\xi}$

(7)

$\Phi(\xi)=\left(1+\mathrm{y}+0.3344 \mathrm{y}^{2}+0.0485 \mathrm{y}^{3}+0.00264 \mathrm{y}^{4}\right) \mathrm{e}^{-\mathrm{y}}$

(8)

$\mathrm{y}=\sqrt{9.67 \xi}$

$\Phi(\xi)=0.35 \mathrm{e}^{-0.3 \xi}+0.55 \mathrm{e}^{-0.55 \xi}+0.1 \mathrm{e}^{-6.0 \xi}$

(9)

$$
\begin{gathered}
\Phi(\xi)=0.02817 \mathrm{e}^{-0.2016 \xi}+0.28018 \mathrm{e}^{-0.4029 \xi}+0.50986 \mathrm{e}^{-0.9423 \xi}+ \\
0.18179 \mathrm{e}^{-3.2 \xi}
\end{gathered}
$$

Most frequent amongst options for a universal screening function $\Phi(\xi)$ are from Bohr eq.(7) [12], Lenz - Jensen eq.(8) [13,14], Moliere eq.(9) [15] and Ziegler et al. eq.(10) [16]. For the screening radius the following options have most frequently been adopted by Lindhard radius eq.(11)[4], Firsov radius eq.(12)[17] and Ziegler et al. radius eq.(13)[16]

$\mathrm{a}_{12}=0.8853 \mathrm{a}_{0} / \sqrt{\mathrm{Z}_{1}^{2 / 3}+\mathrm{Z}_{2}^{2 / 3}}$

$\mathrm{a}_{12}=0.8853 \mathrm{a}_{0} /\left(\mathrm{Z}_{1}+\mathrm{Z}_{2}\right)^{2 / 3}$

$\mathrm{a}_{12}=0.8853 \mathrm{a}_{0} /\left(\mathrm{Z}_{1}^{0.23}+\mathrm{Z}_{2}^{0.23}\right)$

An especially useful is the power approximation of the Thomas - Fermi cross section. The differential cross section is assumed to have power[6] $\mathrm{d} \sigma=\mathrm{CE}^{-\mathrm{m}} \mathrm{T}^{-1-\mathrm{m}} \mathrm{dT}$ 


\section{University of Thi-Qar Journal Vol.11 No.2 June 2016}

Web Site: https://jutq.utq.edu.iq/index.php/main Email: journal@jutq.utq.edu.iq

$\mathrm{d} \sigma_{(1)}=\mathrm{C}_{(1)} \mathrm{E}^{-\mathrm{m}} \mathrm{T}^{-1-\mathrm{m}} \mathrm{dT}$

eq.(15) represents approximately a Thomas - Fermi interaction for any value of $\mathrm{m}$ between 0 and 1 except 0 and a Born-Mayer interaction for $\mathrm{m}=$ 0 [18]. Where $m$ is a numerical constant, $(0 \leq m \leq 1) . m=1$ holds for Rutherford scattering, $\mathrm{m}=\frac{1}{2}$ is a fair approximation over a major portion of the $\mathrm{KeV}$ range and for medium - mass ions and atoms and $\mathrm{m}=\frac{1}{3}$ should be adequate in the lower $-\mathrm{KeV}$ and upper $-\mathrm{eV}$ region[6].

In the $\mathrm{eV}$ region where the Thomas - Fermi potential overestimates the interaction, a Born - Mayer potential may be appropriate, but even in this case, equation may be a reasonable approximation if $\mathrm{m}$ is taken close to zero[19]. The constant $\mathrm{C}$ and $\mathrm{C}_{(1)}$ are well - defined parameter depending on atomic numbers and masses of the collision partners which are given by[6]

$\mathrm{C}=\frac{1}{2} \pi \lambda_{\mathrm{m}} \mathrm{a}_{22}^{2}\left(2 \mathrm{Z}_{1}^{2} \mathrm{e}^{2} / \mathrm{a}_{22}\right)^{2 \mathrm{~m}}$

$\mathrm{C}_{(1)}=\frac{1}{2} \pi \lambda_{\mathrm{m}} \mathrm{a}_{12}^{2}\left(\mathrm{M}_{1} / \mathrm{M}_{2}\right)^{\mathrm{m}}\left(2 \mathrm{Z}_{1} \mathrm{Z}_{2} \mathrm{e}^{2} / \mathrm{a}_{12}\right)^{2 \mathrm{~m}}$

$\mathrm{a}_{12}$ and $\mathrm{a}_{22}$ are Thomas - Fermi screening radii, and $\lambda_{\mathrm{m}}$ are dimensionless constant equal to[6] $\lambda_{1}=0.5, \quad \lambda_{1 / 2}=0.327 \quad$ and $\lambda_{1 / 3}=1.309$. It will be convenient to characterize collisions in the $\mathrm{eV}$ range by a power cross section. For $\mathrm{m}=0$ eqs. $(14,15,16$ and 17$)$ become

$\mathrm{d} \sigma=\mathrm{CdT} / \mathrm{T}$

$\mathrm{d}_{(1)}=\mathrm{C}_{(1)} \mathrm{dT} / \mathrm{T}$

(19)

$\mathrm{C}=\frac{1}{2} \pi \lambda_{0} \mathrm{a}_{22}^{2}$

$\mathrm{C}_{(1)}=\frac{1}{2} \pi \lambda_{0} \mathrm{a}_{12}^{2}$

(21)

For the purpose of numerical evaluations we replace eqs.(20 and 21) by[3]

$\mathrm{C}_{0}=\frac{1}{2} \pi \lambda_{0} \mathrm{a}^{2}$

$\lambda_{0}=24$,

$\mathrm{a}=0.219 \mathrm{~A}^{0}$, 


\section{University of Thi-Qar Journal Vol.11 No.2 June 2016}

Web Site: https://jutq.utq.edu.iq/index.php/main Email: journal@jutq.utq.edu.iq

A part from the differential cross sections, we need the elastic stopping cross section after substituting eq.(14 into 3$)$ and eq.(15 into 3$)$ and integrating them, we get on[3]

$S_{n}(E)=\int_{0}^{E} T d \sigma=\frac{1}{1-m} C E^{1-2 m}$

$\mathrm{S}_{(1) \mathrm{n}}(\mathrm{E})=\int_{0}^{\mathrm{T} m} \mathrm{Td} \sigma_{(1)}=\frac{1}{1-\mathrm{m}} \mathrm{C}_{(1)} \gamma^{1-\mathrm{m}} \mathrm{E}^{1-2 \mathrm{~m}}$

These expressions can be used to define rough energy limits within which cross sections for various values of $m$ apply.

\subsection{Phenomenological Description of Sputtering}

The nuclear stopping process generates displacement cascade in which a large number of higher - order low energy recoil atoms are produced and contributed to sputtering process[2]. The sputtered atoms are those that move toward the surface with sufficient energy to overcome the surface binding forces. These atoms have small ranges therefore it must locate initially within a few atomic layers below the surface[2].

The sputtering yield $\mathrm{Y}$, defined as the average number of target atoms ejected per incident particle, depending on the combination of projectile target variables, including the particle energy $\mathrm{E}$, the atomic numbers and masses of the projectile and the target $\mathrm{Z}_{1}, \mathrm{M}_{1}$ and $\mathrm{Z}_{2}, \mathrm{M}_{2}$ respectively, the structure of the target surface and the experimental geometry $[3,20]$.

The linear cascade theory for Sigmund is used to calculate the sputtering yield [3]. This theory predicts that a linear dependence of $Y$ on the energy deposited in displacement cascade at the surface of a random, $F_{D}(E, \theta, 0)[2]$ : $\mathrm{Y}(\mathrm{E})=\Lambda \mathrm{F}_{\mathrm{D}}(\mathrm{E}, \theta, 0)$

$\Lambda=\frac{X_{0}}{\pi^{2} U}$

By substituting eq.(25) into eq.(26), sputtering yield $\mathrm{Y}$ becomes[2]

$\mathrm{Y}(\mathrm{E})=\frac{\mathrm{X}_{0}}{\pi^{2} \mathrm{U}} \mathrm{F}_{\mathrm{D}}(\mathrm{E}, \theta, 0)$

$\mathrm{X}_{0}=\frac{3}{4 \mathrm{NC}_{0}}$ 


\section{University of Thi-Qar Journal Vol.11 No.2 June 2016}

Web Site: https://jutq.utq.edu.iq/index.php/main Email: journal@jutq.utq.edu.iq

The constant $\Lambda$ is a material constant, including the surface binding energy and a cross section for target atoms colliding with each other at low energies[11]. $\mathrm{X}_{0}$ is the effective depth of origin of the sputtered atoms[2] and $\mathrm{U}$ is the surface binding forces. By substituting eq.(28) into eq.(26), we get[10]

$\Lambda=\frac{3}{4 \pi^{2} \mathrm{NC}_{0} \mathrm{U}}$

where $\mathrm{C}_{0}$ is a constant governing the low - energy stopping cross section given in eq.(22) for $\mathrm{m}=0$, by using the conventional value of $\lambda_{0}=24$ and $\mathrm{a}=0.0219 \mathrm{~nm}$ (Born - Mayer constant). Hence, $\mathrm{C}_{0}=0.0181 \mathrm{~nm}^{2}[3]$. The substitution the value of $\mathrm{C}_{0}$ into eq.(29), it becomes[3]

$\Lambda=\frac{0.0420}{\mathrm{~N} \mathrm{U} \mathrm{A}^{2}}$

The surface deposited energy $F_{D}(E, \theta, 0)$ can be obtained from the depth distribution of the energy deposited in nuclear collisions in the solid, $F_{D}(E, \theta, X)$, by an incident particle of energy $E$ aligned at an angle $\theta$ with respect to the surface normal ( $\mathrm{x}$ - direction) [2]

$\mathrm{F}_{\mathrm{D}}(\mathrm{E}, \theta, 0)=\alpha \mathrm{NS}_{\mathrm{n}}(\mathrm{E})$

After substituting eq.(31) into eq. (25), Sigmund uses a linear Boltzmann transport equation for the well - known expression of the sputtering yield from a planar surface is[3]

$\mathrm{Y}(\mathrm{E})=\Lambda \alpha \mathrm{NS}_{\mathrm{n}}(\mathrm{E})$

$S_{n}(E)$ is the only quantity entering eq.(32) that depends on the ion - target interaction cross section[3]. For $\mathrm{m}=0$, the elastic stopping cross section $\mathrm{S}_{\mathrm{n}}(\mathrm{E})$ given by eq.(24) becomes [6]

$\mathrm{S}_{\mathrm{n}}(\mathrm{E})=\mathrm{C}_{0} \gamma \mathrm{E}$

$\mathrm{S}_{\mathrm{n}}(\mathrm{E})=\mathrm{C}_{0} \mathrm{~T}_{\mathrm{m}}$

with $\mathrm{T}_{\mathrm{m}}=\gamma \mathrm{E}$

From eqs.(29 and 34), the sputtering field in eq.(32) at perpendicular incidence is[3] 


\section{University of Thi-Qar Journal Vol.11 No.2 June 2016}

Web Site: https://jutq.utq.edu.iq/index.php/main Email: journal@jutq.utq.edu.iq

$\mathrm{Y}(\mathrm{E})=\left(\frac{3}{4 \pi^{2}}\right) \alpha \mathrm{T}_{\mathrm{m}} / \mathrm{U}$

This expression does not depend on either $\lambda_{0}$ or a. A part from the mass number $\mathrm{M}_{2}$ and $\mathrm{U}$ is the only target property that enters eq.(35) [3].

where $\alpha$ is a numerical factor depending primarily on the mass ratio $\left(\mathrm{M}_{2} / \mathrm{M}_{1}\right)$ and the angle $\theta$ of the incident and $\alpha$ is relatively insensitive for variations in the primary energy $\mathrm{E}$ [2]. For $\left(\mathrm{M}_{2} / \mathrm{M}_{1} \leq 0.5\right), \alpha$ is nearly constant $\sim 0.2$. However, it rises sharply with increasing $\left(M_{2} / M_{1}>0.5\right)$. Within the range of $\left(0.5<\mathrm{M}_{2} / \mathrm{M}_{1} \leq 10\right), \alpha$ can be approximated by [21] $\alpha=0.3\left(\mathrm{M}_{2} / \mathrm{M}_{1}\right)^{2 / 3}$

The nuclear stopping cross section $S_{n}(E)$ increases approximately linearly with $\mathrm{E}$ at very low energies $(\mathrm{m} \cong 0)$, reaches a (maximum) plateau at intermediate energies $(\mathrm{m} \cong 1 / 2)$, and then decreases at higher energies $(1 / 2<\mathrm{m} \leq 1)[2]$.

We take the expression of Lindhard et al. to calculate the nuclear stopping cross section $S_{n}(E)$ by assuming Thomas - Fermi interaction[6].

$\mathrm{S}_{\mathrm{n}}(\mathrm{E})=\frac{4 \pi \mathrm{Z}_{1} \mathrm{Z}_{2} \mathrm{e}^{2} \mathrm{a}_{12} \mathrm{M}_{1}}{\left[\mathrm{M}_{1}+\mathrm{M}_{2}\right]} \mathrm{S}_{\mathrm{n}}(\varepsilon)$

where $S_{n}(\varepsilon)$ is the reduced nuclear stopping cross section. For $\varepsilon \geq 10^{-3}$, $\mathrm{S}_{\mathrm{n}}(\varepsilon)$ can also be calculated analytically using the following expression derived recently by Matsunami et al.[22]

$\mathrm{S}_{\mathrm{n}}(\varepsilon)=\frac{3.44 \varepsilon^{1 / 2} \log (\varepsilon+2.718)}{1+6.355 \varepsilon^{1 / 2}+\varepsilon\left(6.882 \varepsilon^{1 / 2}-1.708\right)}$

$\varepsilon=\frac{\mathrm{M}_{2} \mathrm{E}}{\mathrm{M}_{1}+\mathrm{M}_{2}} \cdot \frac{\mathrm{a}_{12}}{\mathrm{Z}_{1} \mathrm{Z}_{2} \mathrm{e}^{2}}$

where $\mathrm{a}_{12}$ is the Lindhard's screening radius given by eq.(11), $\mathrm{a}_{0}=0.0529$ $n m$ (Bohr radius), $E$ is the energy in $\mathrm{KeV}$, masses $\mathrm{M}_{1}$ and $\mathrm{M}_{2}$ are in amu., and $\varepsilon$ is the reduced energy .

\subsection{The Sputtering Process}

The interaction of fast ions with a crystalline solid has a number of results. The kinetic energy of the incoming ions is transferred to the atoms and electrons of the target. Some ions may be backscattered from the target 


\section{University of Thi-Qar Journal Vol.11 No.2 June 2016}

Web Site: https://jutq.utq.edu.iq/index.php/main Email: journal@jutq.utq.edu.iq

and the rest stop within it. If the kinetic energy transferred to a target atom is enough, it causes to displace it from its lattice site with substantial energy generating more recoiling atoms to slow down in their turn, until the initial kinetic energy of the primary ion is completely dissipated. Some recoiling atoms may reach the target surface with enough kinetic energy to escape from it. They are mostly neutral atoms ejected in a wide angular distribution which contain important information about the solid, some ejected atoms are in excited state which may accompany with by small number of ions[23].

The atom in a monatomic medium is displaced with an initial kinetic energy $E_{0}$. By differentiation, the number of new recoils with kinetic energies between $E_{1}$ and $E_{1}+d E_{1}$ is proportional to $\left(1 / E_{1}^{2}\right)[24]$. In Thomson for the energy spectrum of the sputtered atoms is proportional to [23]

$\mathrm{F}\left(\mathrm{E}_{1}\right)=\frac{\mathrm{E}_{1}}{\left(\mathrm{E}_{1}+\mathrm{U}\right)^{3}}$

It is found that the high - energy tail of those EDF's decreased inversely proportional to the square of the particle energy[8]. This formula was derived assuming that sputtered atoms come from a well-developed collision cascade in a material. This cascade is generated by a heavy ion bombardment. He actually measured the EDF for several poly - crystalline metal targets[8]. EDF can be written as[8]

$F\left(E_{1}\right)=\frac{1-\sqrt{E_{1}+U / \gamma E_{i n c}}}{E_{1}^{2}\left(1+\frac{U}{E_{1}}\right)^{3}}=\frac{1-\sqrt{E_{1}+U / \gamma E_{i n c}}}{E_{1}^{2}\left(\frac{U+E_{1}}{E_{1}}\right)^{3}}$

$\mathrm{F}\left(\mathrm{E}_{1}\right)=\frac{\mathrm{E}_{1}}{\left(\mathrm{E}_{1}+\mathrm{U}\right)^{3}}\left(1-\sqrt{\frac{\mathrm{E}_{1}+\mathrm{U}}{\gamma \mathrm{E}_{\text {inc }}}}\right)$

where $E_{1}$ and $E_{i n c}$ are the energies of sputtered atoms and incident ions, notice that, eq.(40) is reduced to eq.(43) when $\gamma E_{\text {inc }}>E_{1}$. The maximum in the energy distribution is reached at $\mathrm{U} / 2$ and can be found from experimentally measured energy distributions of sputtered atoms[25]. The energy distributions of sputtered atoms peak in lower energy that was explained by a contribution of primary recoil atoms[26]. The dependence of 


\section{University of Thi-Qar Journal Vol.11 No.2 June 2016}

Web Site: https://jutq.utq.edu.iq/index.php/main Email: journal@jutq.utq.edu.iq

the energy distribution of sputtered particles on ion energy and ion type has been systematically simulated by Biersack and Eckstein[27].

\section{Results and Discussion}

Figure(1) shows the results of universal screening function as a function of ( $\mathrm{r} / \mathrm{a})$ that are obtained from Bohr eq.(7) [12], Lenz - Jensen eq.(8) [13,14], Moliere eq.(9) [15] and Ziegler et al. eq.(10) [16]. From the figure, it is noted that all results of universal screening function are comparable in magnitude at low values of $(\mathrm{r} / \mathrm{a})$, while the results are divergent at high values of $(r / a)$ except the results from Lenz - Jensen and Ziegler et al. which remain nearly comparable in magnitude at all values of $(r / a)$. The Lenz - Jensen potential are found to represent a considerable approximation to experimental scattering cross section, but deviation from universal behavior are comparable in magnitude to the difference between Moliere and Lenz - Jensen.

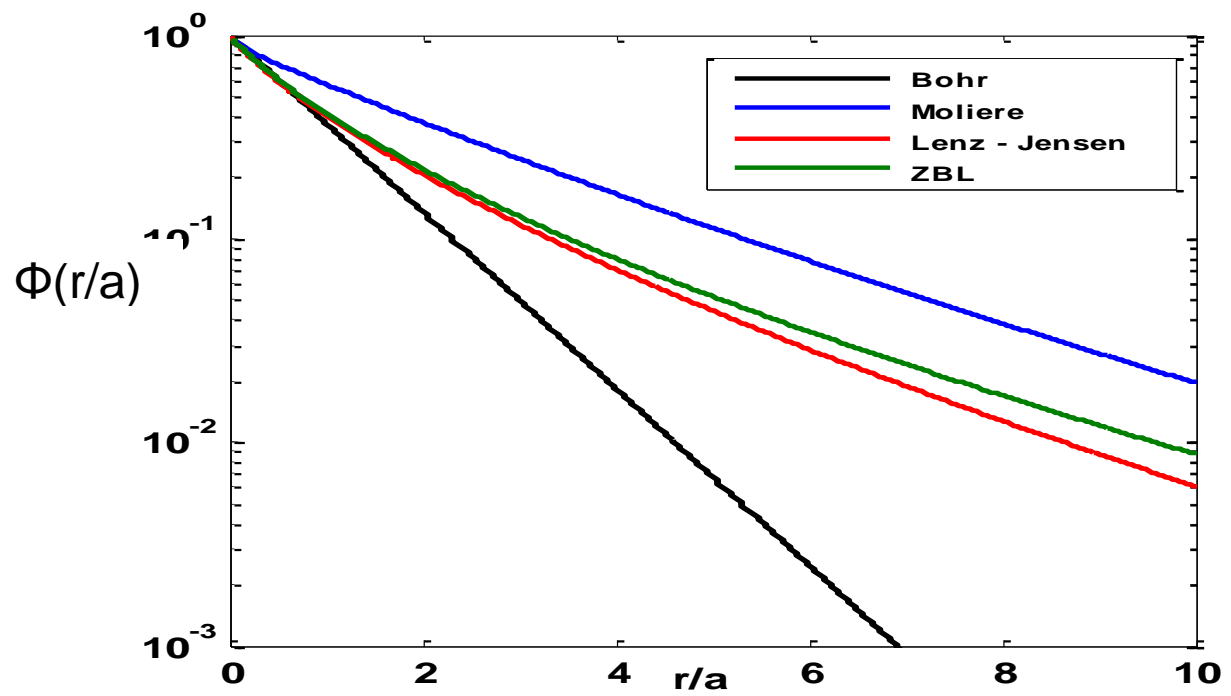

Figure (1) Universal screening functions employed in calculations of elastic collisions

Figure (2) shows the ratio of screening radii versus $\mathrm{Z}_{1} / \mathrm{Z}_{2}$. The ratio of screening between Lindhard radius [4] and Firsov radius [17] (Lindhard/Firsov) is obtained from eqs.(11 and 12). It is noted that the Lindhard radius differs from Firsov radius by nearly $12 \%$. The figure also explains the ratio of screening between Lindhard radius[4] and Ziegler et al. radius [16] (Lindhard/ZBL) which is evaluated from eqs.(11 and 13) and 


\section{University of Thi-Qar Journal Vol.11 No.2 June 2016}

Web Site: https://jutq.utq.edu.iq/index.php/main Email: journal@jutq.utq.edu.iq

calculated for various values of atomic number of target $Z_{2}=(100,10$, and 1). It is seen that the ratio screening effects with $Z_{2}$ and it is proportional parallel with it therefore, the values of screening ratio at high $\mathrm{Z}_{2}$ are greater than that at low $Z_{2}$. The figure also shows that for the Ziegler et al. radius, the difference between Lindhard radius and Ziegler et al. radius is much more evident.

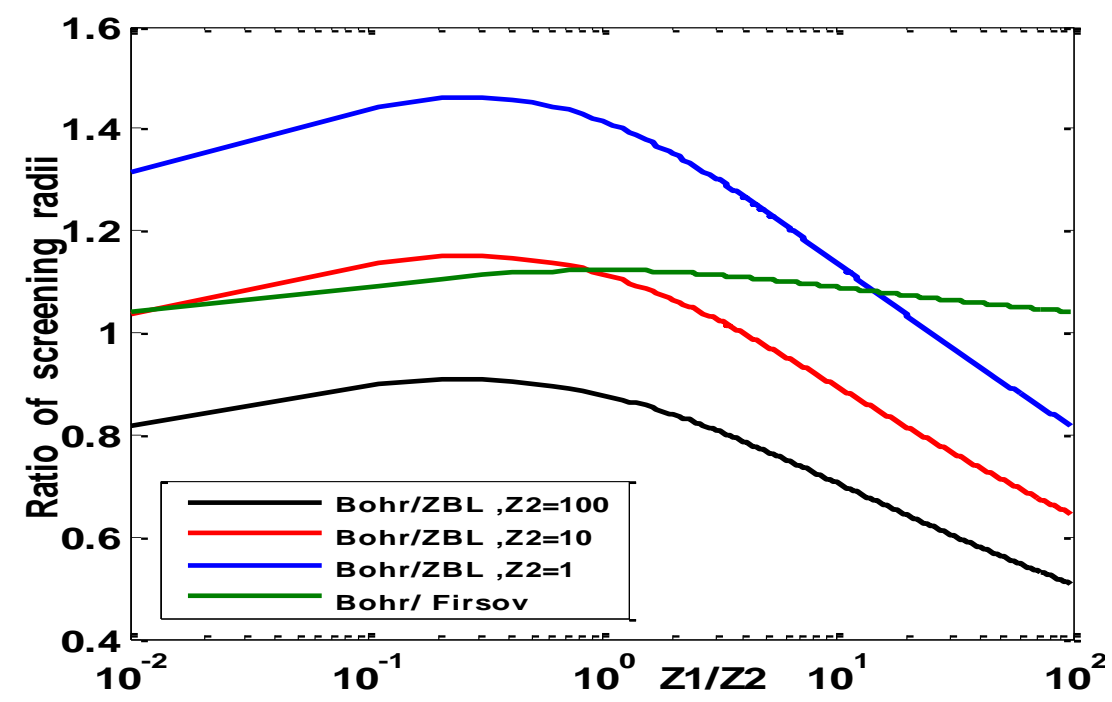

Figure(2) Ratio of screening radii

Figure (3) show the results of sputtering yields of polycrystalline $\mathrm{Cu}$ with binding energy $(\mathrm{U}=3.51 \mathrm{eV}), \mathrm{Z}_{2}=29$ and mass ratios is from about 0.5 to 3 , while the figure (4) explains yields for Ag with binding energy $(\mathrm{U}=2.96 \mathrm{eV}), \mathrm{Z}_{2}=47$ and mass ratios from about 0.8 to 5 but the figure (5) shows a similar curve of yield for $\mathrm{Pd}$ to Ag with binding energy $(\mathrm{U}=3.9 \mathrm{eV}), \mathrm{Z}_{2}=46$ and mass ratios from about 0.8 to 5. All the curves are calculated for different incident noble gas ions $(\mathrm{Xe}, \mathrm{Kr}, \mathrm{Ar}$ and $\mathrm{Ne})$ with atomic number $\left(\mathrm{Z}_{1}=54,36,18\right.$, and 10) versus ion energy. The sputtering yields are evaluated from Born - Mayer interaction at ion energies smaller than $1 \mathrm{KeV}$ in eq.(35). The yield increases with increasing ion energy $\mathrm{E}$ at low energy where $\mathrm{m}$ is close to zero. One must regard that the incident ion is a light ion in order to check the validity of $\alpha$ versus $\mathrm{M}_{2} / \mathrm{M}_{1}$ curve for larger values of $\mathrm{M}_{2} / \mathrm{M}_{1}$. The yield curves are linear at energies below $100 \mathrm{eV}$ but in the energy range larger than $100 \mathrm{eV}$, the yield curves are not really linear because of the supposition of an infinite medium and neglect the scattering out of the surface. 
University of Thi-Qar Journal Vol.11 No.2 June 2016

Web Site: https://jutq.utq.edu.iq/index.php/main Email: journal@jutq.utq.edu.iq
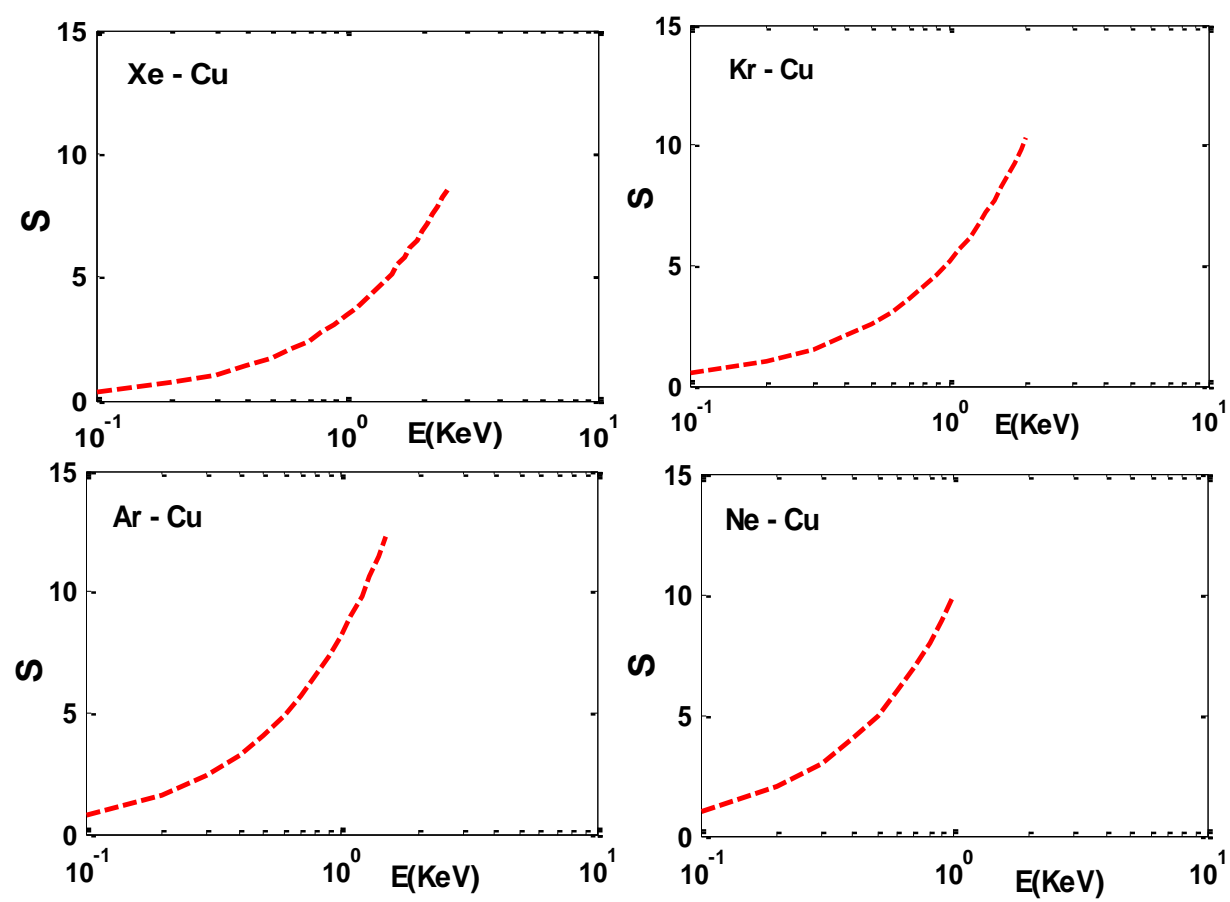

Figure(3)Sputtering yields for $\mathrm{Cu}$ calculated from eq.(35) with $\mathrm{Xe}, \mathrm{Kr}$, Ar, Ne ions
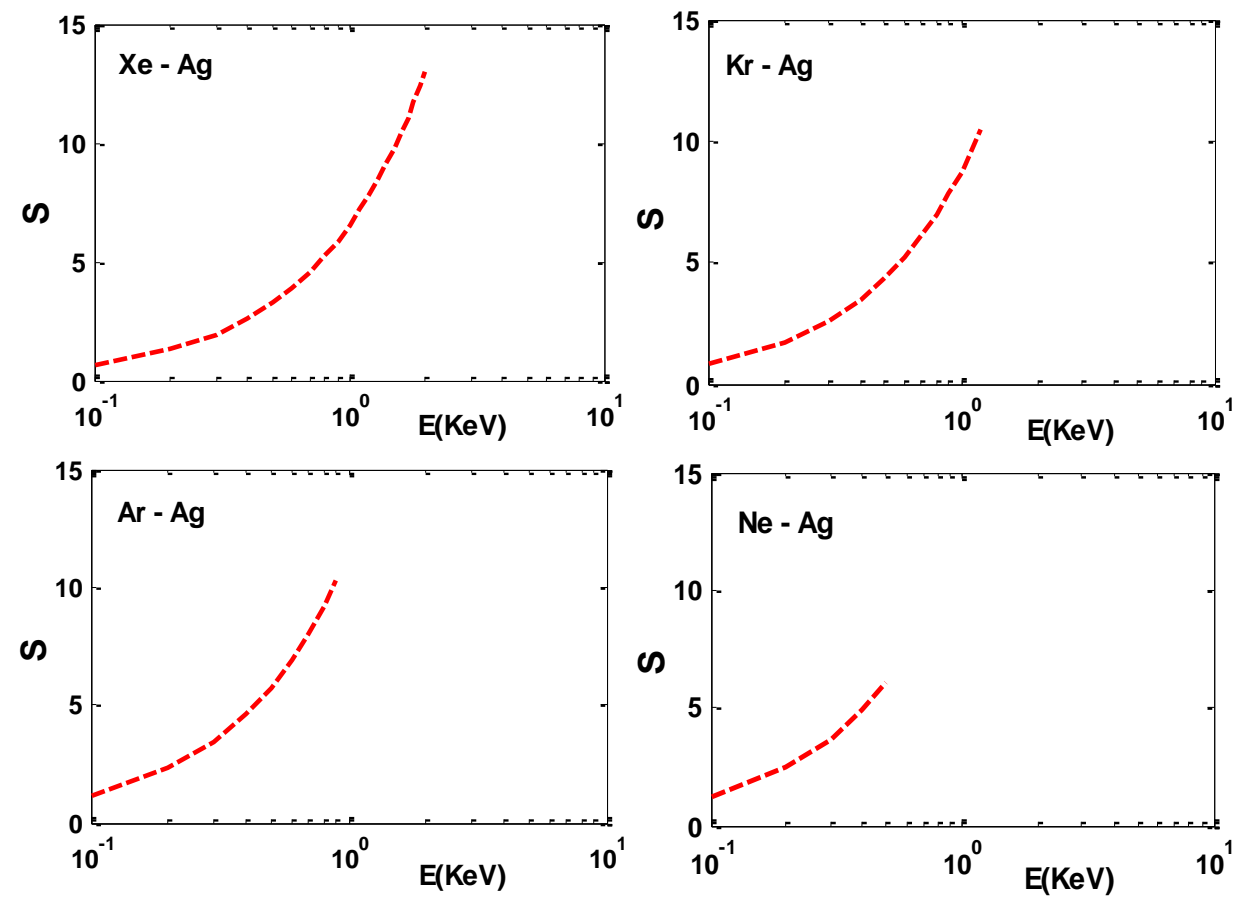
Figure(4)Sputtering yields for Ag calculated from eq.(35) with $\mathrm{Xe}, \mathrm{Kr}$, Ar, Ne ions
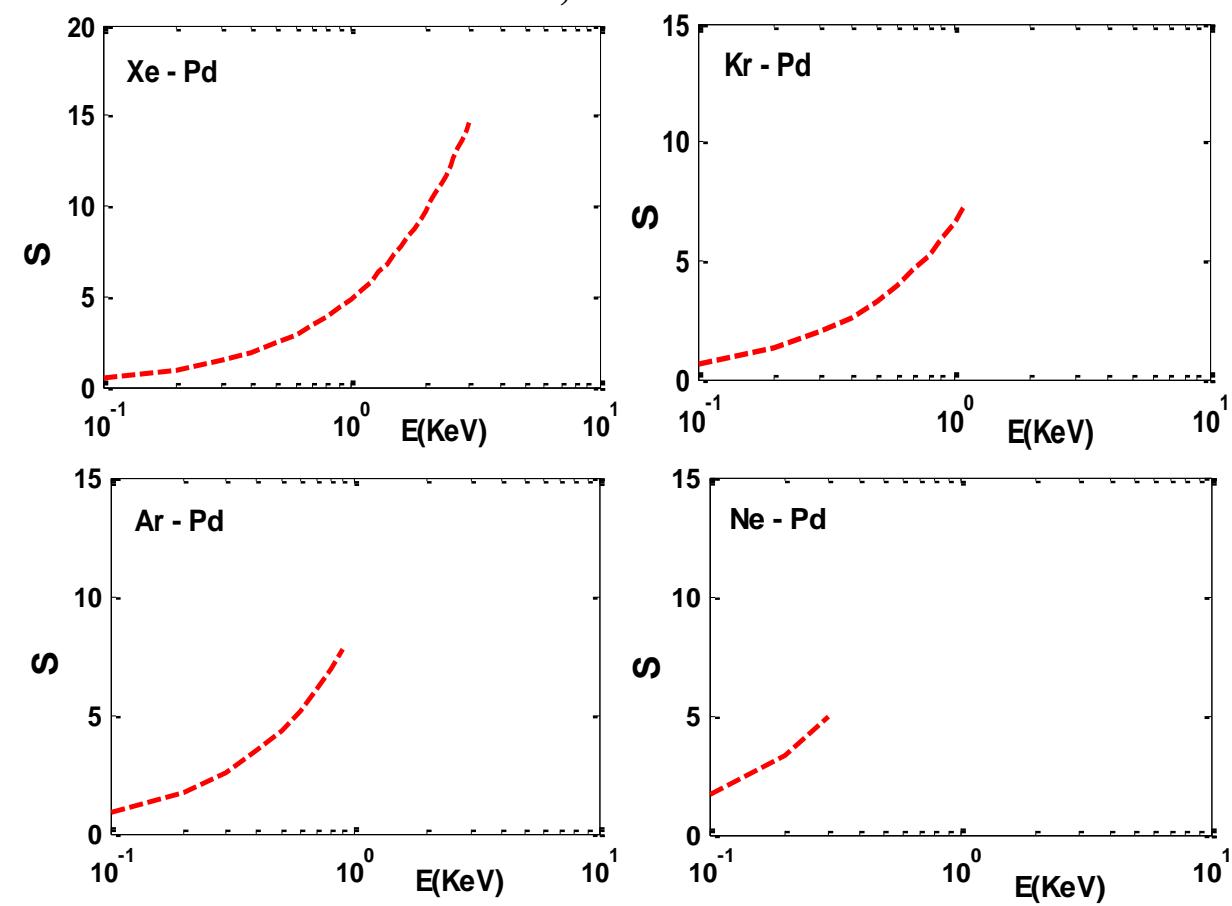

Figure(5)Sputtering yields for Pd calculated from eq.(35) with $\mathrm{Xe}, \mathrm{Kr}$, Ar, Ne ions

Figure(6) shows sputtering yields of polycrystalline $\mathrm{Cu}$ with binding energy $(\mathrm{U}=3.51 \mathrm{eV})$ and $\mathrm{Z}_{2}=29$ for different incident noble gas ions (Xe, $\mathrm{Kr}, \mathrm{Ar}$ and $\mathrm{Ne}$ ) with atomic number $\left(\mathrm{Z}_{1}=54,36,18\right.$, and 10) versus ion energy in (KeV). Sputtering yield is obtained from Thomas Fermi interaction at ion energies larger than order of some hundred eV in eq.(37). From the figure, it is seen that the there is a variation in yield with ion energy which reflects the sputtering yield should be proportional to the energy lost by the incoming ions. At low velocities, sputtering yields increase with increasing ion energy but then approach a maximum and ultimately decrease again at high energies. For a fixed target, the maximum in the sputtering yield appears to be more pronounced for very heavy ions because of the nonlinear effects in very dense collision cascade than that predicted for light ions because of the lack a surface correction term. For a fixed target material, the sputtering yield is a monotonically increasing function of atomic number of 
Web Site: https://jutq.utq.edu.iq/index.php/main Email: journal@jutq.utq.edu.iq ion $\mathrm{Z}_{1}$ therefore, the greater the yield, the heavier the ion (Xe) and the smaller the yield, the lighter the ion $(\mathrm{Ne})$. The sputtering yield is overestimated probably for Ne because of the neglect of the surface.
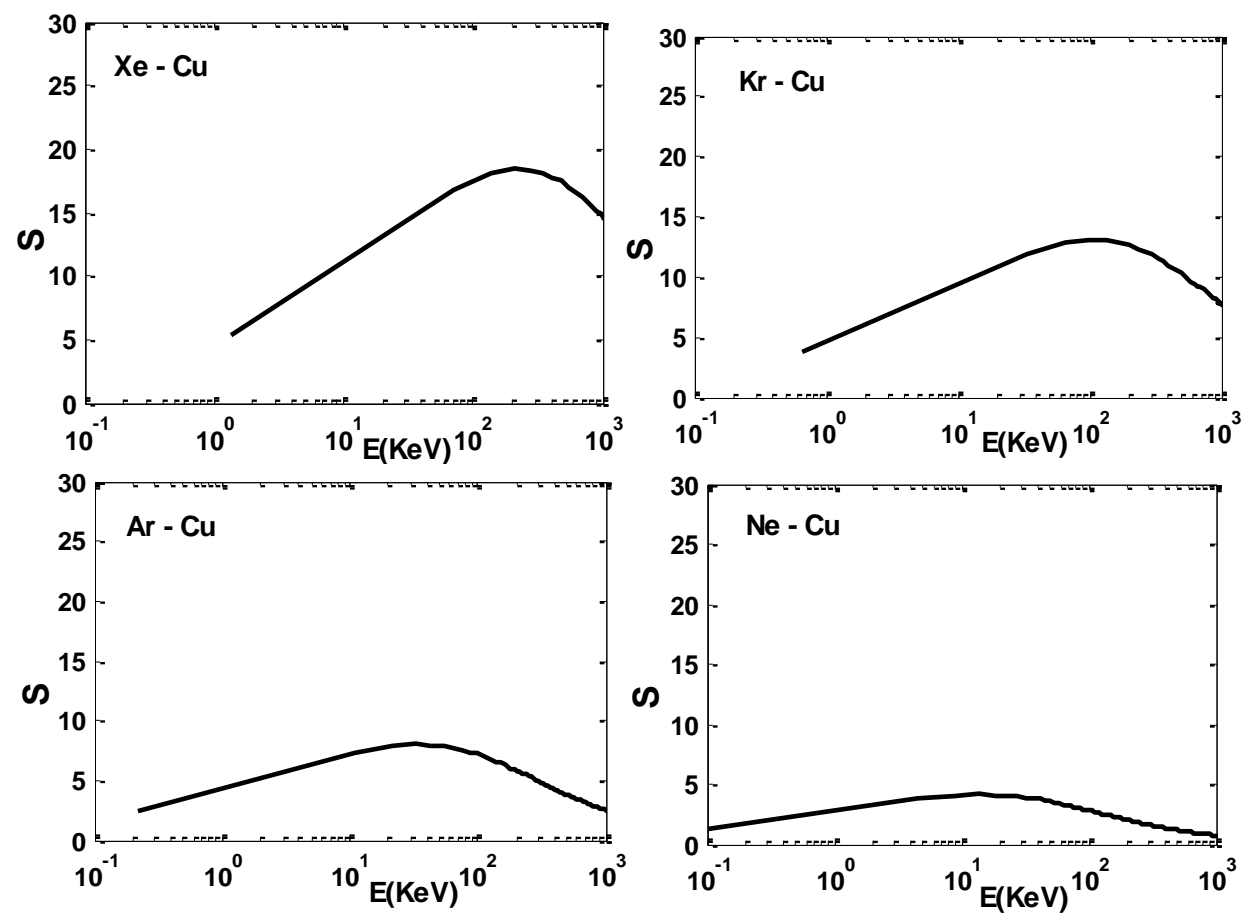

Figure(6)Sputtering yields for $\mathrm{Cu}$ calculated from eq.(37) with $\mathrm{Xe}, \mathrm{Kr}$,

\section{Ar, Ne ions}

Figure(7) shows a similar curve of yield for Ag with binding energy $(\mathrm{U}=2.96 \mathrm{eV})$ and $\mathrm{Z}_{2}=47$. The $(\mathrm{Xe}-\mathrm{Ag}),(\mathrm{Kr}-\mathrm{Ag})$ and $(\mathrm{Ar}-\mathrm{Ag})$ curves have a tendency to underestimate the yield except for $(\mathrm{Ne}-\mathrm{Ag})$.
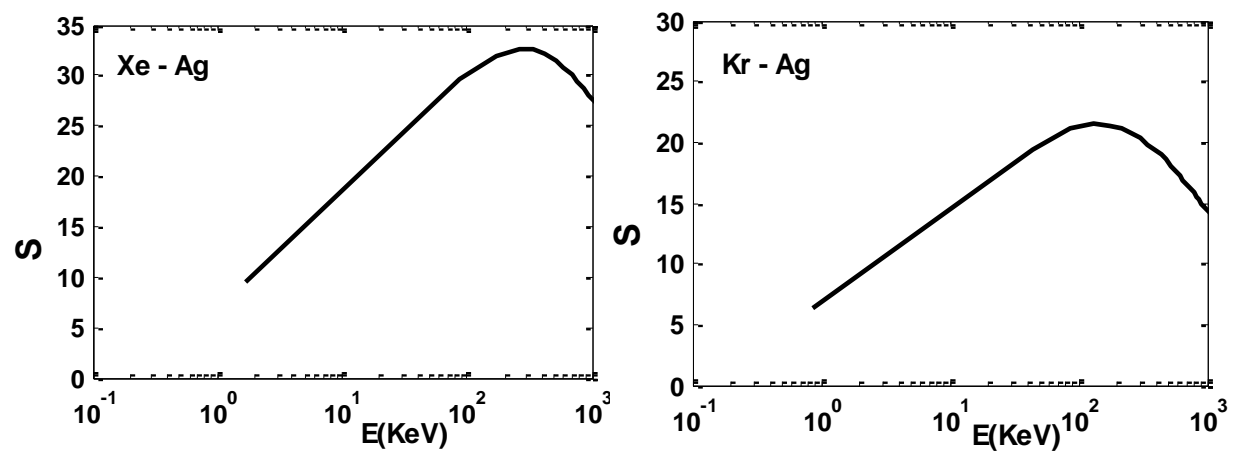
University of Thi-Qar Journal Vol.11 No.2 June 2016

Web Site: https://jutq.utq.edu.iq/index.php/main Email: journal@jutq.utq.edu.iq
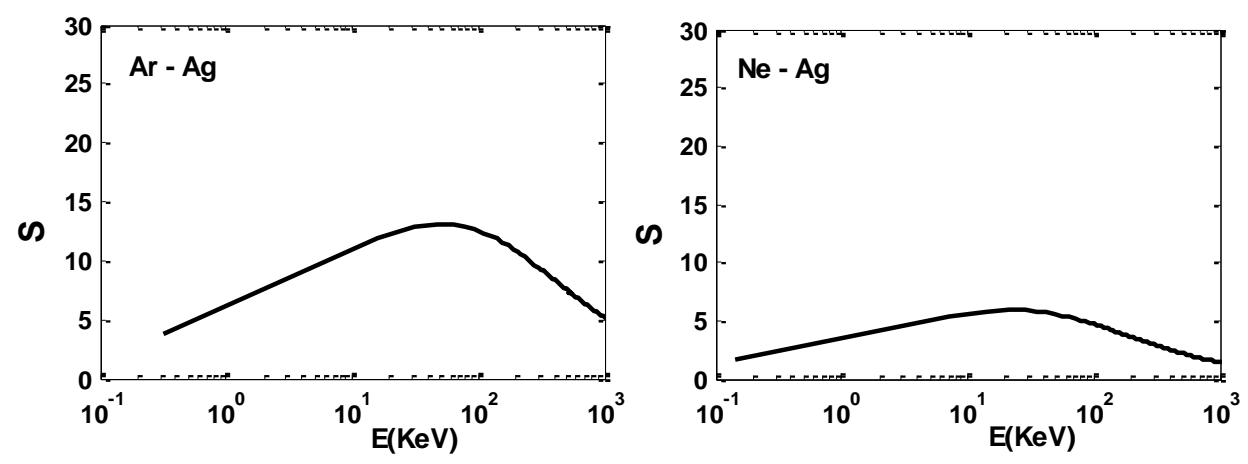

Figure(7)Sputtering yields for Ag calculated from eq.(37) with $\mathrm{Xe}, \mathrm{Kr}$, Ar, Ne ions

Figure(8) shows a similar curve of yield for $\mathrm{Pd}$ which is a very similar metal to $\mathrm{Ag}$ with binding energy $(\mathrm{U}=3.9 \mathrm{eV})$ and $\left.\mathrm{Z}_{2}=46\right)$. The reverse is true in the case of $\mathrm{Pd}$. The $(\mathrm{Xe}-\mathrm{Pd}),(\mathrm{Kr}-\mathrm{Pd})$ and $(\mathrm{Ar}-\mathrm{Pd})$ curves tend to overestimate the sputtering yield except for $(\mathrm{Ne}-\mathrm{Pd})$.
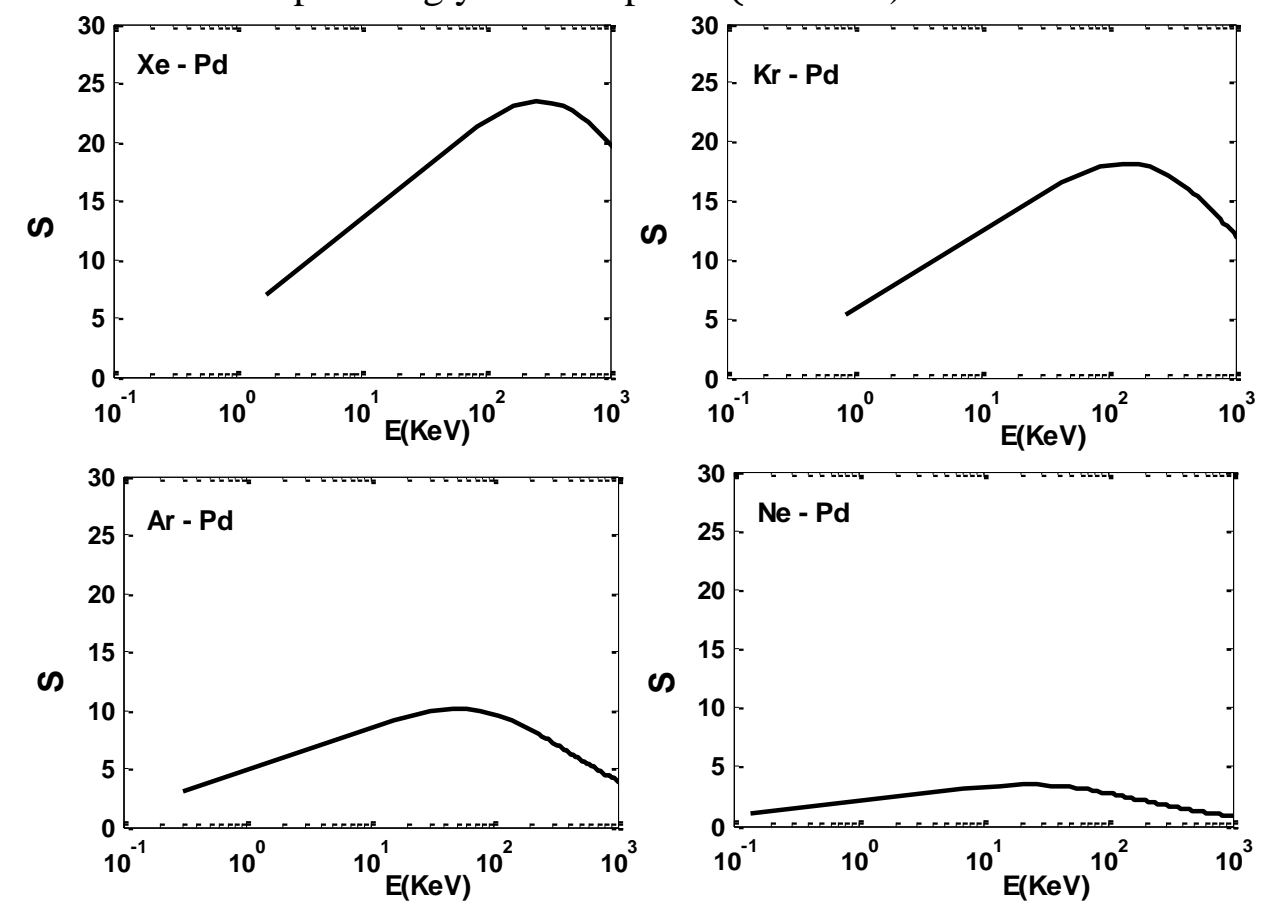

Figure(8)Sputtering yields for Pd calculated from eq.(37) with $\mathrm{Xe}, \mathrm{Kr}$, Ar, Ne ions 
Figure(9) shows the results of energy spectra $F\left(E_{1}\right)$ of sputtered atoms $\mathrm{Cu}$ that obtained from eq.(43) versus energy of sputtered atoms for $\mathrm{Kr}$ ions with different values of energy $E_{\text {inc }}=(80,150,300,600$, and 1200) $\mathrm{eV}$. The figure confirms that the energy spectrum of moving sputtered atoms is proportional to $1 / E_{1}^{2}$. It is clear the spectrum diverges for small energies which means that as the collision cascade develops in time and the energy of incident ion is shared between more and more recoiling atoms because the linearity of cascade collisions fail at low recoil energies and the linear transport theory is no valid. Substantial deviations from an $1 / E_{1}^{2}$ recoil atom energy spectrum must occur at higher energies, the higher the density of the cascade. In each curve, the energy spectrum has a maximum at $\mathrm{U} / 2$ $(\mathrm{eV})$ and tail extending to tens and hundreds of $(\mathrm{eV})$. From the curves, the maximum position is an increasing function of the incident energy, hence the spectrum of sputtered atoms increases with increasing incident ion energy, therefore at ion energy $1200 \mathrm{eV}$, the spectrum has greater values than that at other ion energies.

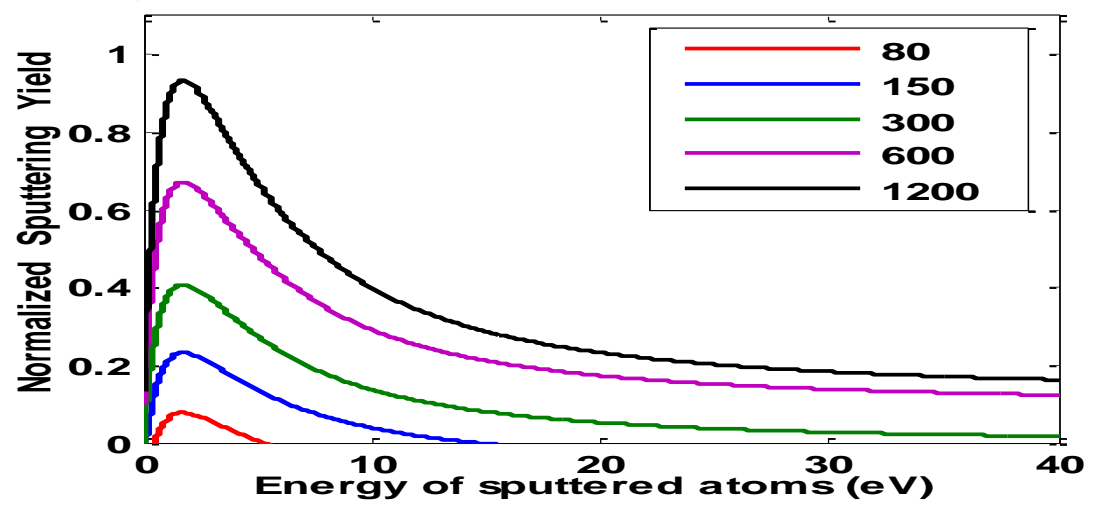

Figure(9) Normalized yield of atoms sputtered from Cu material irradiated by $\mathrm{Kr}$ ions at normal incidence

Figure(10) shows the ratio $\mathrm{F}\left(\mathrm{E}_{1}\right) / \mathrm{F}_{\max }$ of sputtered atoms $\mathrm{Cu}$ versus energy of sputtered atoms for $\mathrm{Kr}$ ions with energy $\mathrm{U} / 2$. The figure demonstrates that the energy spectrum of sputtered atoms has a peak at $1 \sim \mathrm{eV}$. 


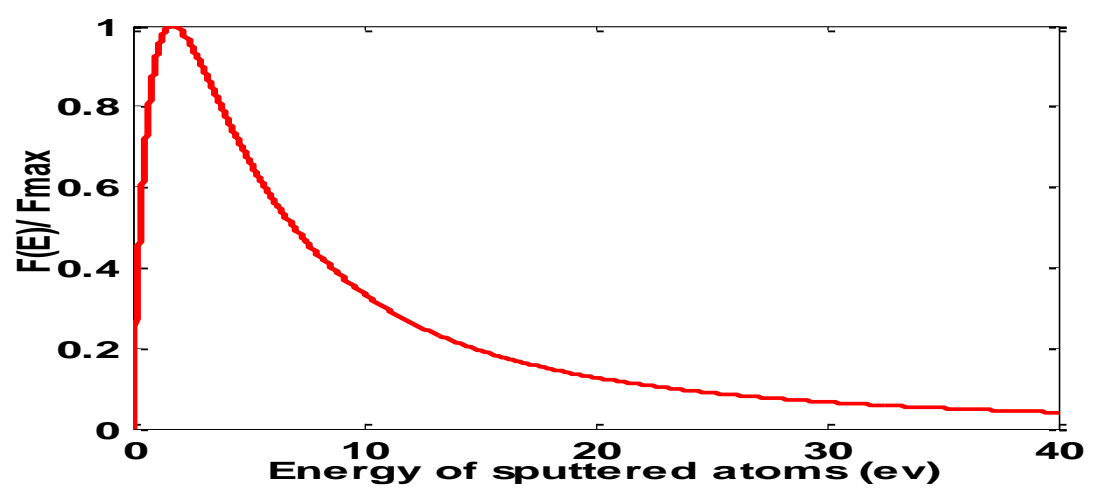

Figure(10) Ratio $\mathrm{F}\left(\mathrm{E}_{1}\right) / \mathrm{F}_{\max }$ of atoms sputtered from $\mathrm{Cu}$ material irradiated by $\mathrm{Kr}$ ions at normal incidence

\section{Conclusions}

Sputtering is the target atoms removed from the surface (in other words, the ions detach atoms from the target because of nuclear stopping) by a sequence of collisions cascade between a projectile and the atoms in the near surface layers of target material which causes a destruction of solid state and leads to the emission of atomic particles (a number of primary and higher order recoiling atoms). The recoil atoms are large number of target atoms displacing from their equilibrium positions when the energy and momentum of the ions transfer to the target atoms.

There is a necessary condition for sputtering that $\mathrm{E}>\mathrm{U}$ (the ion energy is larger than the surface binding energy). If the energy of the recoil atoms is larger than the surface binding energy $U$, the recoil atoms reach the surface (sputtered atoms) and lose its remaining kinetic energy as heat.

Sputtering yield is the number of sputtered atoms per incoming ion and it is obtained from the weight loss of target and the number of incoming ions. Sigmund assumption of sputtering theory is based on that all the binary collisions within the cascade take place between a moving and a fixed atom and he uses the linear Boltzmann equation to describe these collisions. In the sputtering by elastic collisions which initiated by ion bombardment, it is necessary to determine the nuclear stopping cross section in the low energy regimes in order to evaluate the sputtering yield. The stopping cross section for elastic collisions can be calculated from Thomas - Fermi interaction at high energies (upper $\mathrm{eV}$ and in $\mathrm{KeV}$ ) for $0<\mathrm{m} \leq 1$ and Born - Mayer interaction at low energies (in $\mathrm{eV}$ ) for $\mathrm{m}=0$. 


\section{University of Thi-Qar Journal Vol.11 No.2 June 2016}

Web Site: https://jutq.utq.edu.iq/index.php/main Email: journal@jutq.utq.edu.iq

Sputtering yields are proportional to energy of ion. The dependence of sputtering yield on ion energy is proportional to the nuclear stopping power and the magnitude of yield increases with increasing ion energy at low ion energy $E$ where $m=0$, conversely, at high ion energy $E$ where $m=1$, the yield decreases with increasing ion energy $E$. Since $m$ runs from 0 to 1 with increasing ion energy, it is noted that the yields have the maximum at intermediate energy. That maximum lies at $\mathrm{KeV}$ energies, and it magnitude increases strongly with projectile and target mass, therefore the maximum in the sputtering yield is due to nonlinear effect and more obvious for heavy projectiles than for light projectiles which is ascribed to the lack of surface correction.

The variation of sputtering with ion type reflects the influence of projectile atomic number $\mathrm{Z}_{1}$ on sputtering yield which increases monotonically with $\mathrm{Z}_{1}$. For a same target material $\left(\mathrm{Z}_{2}\right)$ and various projectile $\mathrm{Z}_{1}$, the larger the sputtering yield, the heavier the projectile (large $\mathrm{Z}_{1}$ ) and the smaller the sputtering yield, the lighter the projectile (small $\mathrm{Z}_{1}$ ).

The energy spectrum of sputtered particles which represent mainly the recoil atoms from a heavy ions hit a solid target surface may be described by Thompson formula. The recoil atoms reproduce from the collision cascade when the ions interact with a target atoms and deposit the energy near the surface causing the recoil atoms to leave the surface if they receive enough energy to overcome the surface binding energy. The energy spectrum of sputtered particles exhibits a maximum at $E_{1}=U / 2$ at lower energies and falls off in proportion to $1 / E_{1}^{2}$ which can be affected by many factors, including ion energy and ion type.

\section{References}

[1] P. Sigmund, Recollections of Fifty Years with Sputtering, Thin Solid Films, Vol.520, pp.6031- 6049 (2012).

[2] N. Q. Lam, Physical Sputtering Of Metallic Systems By Charged Particle Impact, Scan. Microsc. Suppl., Vol.4, pp.311 - 352 (1990).

[3] P. Sigmund, Theory of Sputtering. I. Sputtering Yield of Amorphous and Polycrystalline Targets, phys. Rev, Vol.184, no.2, pp.383 - 416 (1969).

[4] J. Lindhard, M. Scharff, and H .E. Schott, Range concepts and heavy ion ranges, Mat. Fys. Medd. Dan. Vid. Selsk.,Vol.33, no.14 (1963). 


\section{University of Thi-Qar Journal Vol.11 No.2 June 2016}

Web Site: https://jutq.utq.edu.iq/index.php/main Email: journal@jutq.utq.edu.iq

[5] P. Sigmund, Theory of Sputtering. I. Sputtering Yield of Amorphous and Polycrystalline Targets, phys. Rev, Vol.187, pp.768 (1969).

[6] J. Lindhard, V. Nielsen and M. Scharff, Approximation method in classical scattering by screened coulomb fields, Mat. Fys. Medd. Dan. Vid. Selsk., Vol.36, no.10 (1968).

[7] J. B. Sanders, On penetration depths and collision cascades in solid materials, Ph. D. thesis, University of Leiden (1968).

[8] M.W. Thompson, Energy spectrum of ejected atoms during high energy sputtering of gold, Philos. Mag., Vol.18, pp.377 (1968)

[9] H.L. Bay, B. Schweer, P. Bogen, and E. Hint, Investigation of Light Ion Sputtering of Titanium Using Laser Induced Fluorescence, J. Nucl. Mater., Vol. 111 and 112, pp.732 (1982).

[10] J. Schou, "Slowing down processes, energy deposition, sputtering and desorption in ion and electron interactions with solids", in Vacuum in accelerators, Ed by Daniel Brandt, Geneva , Switzerland, Vol. CERN-2007003, pp.169 - 178 (2007).

[11] P. Sigmund, Elements of Sputtering Theory, (Pan Stanford Publishing Pte, Ltd: PSP Review Volume, (2011).

[12] N. Bohr, The penetration of atomic particles through matter, Mat. Fys. Medd. Dan. Vid. Selsk. Vol.18, no.8, pp.1 - 144 (1948).

[13] W. Lenz, Uber die Anwendbarkeit der statistischen Methode auf Ionengitter Z. Physik, Vol.77, pp.713 (1932).

[14] H. Jensen, Die Ladungsverteilung in Ionen und die Gitterkonstante des Rubidiumbromids nach der statistischen Methode, Z. Physik, Vol.77, pp.722 (1932).

[15] G. Moliere, Theorie der Streuung schneller geladener Teilchen I . Einzelstreuung am abgeschirmten Coulomb - Feld, Z. Naturforsch. 2a , pp. 133 - 145 (1947).

[16] J. F. Ziegler, J. P. Biersack, and U. Liltmark, The Stopping and Range of Ions in Matter, Vol.1 (Pergamon, New York, 1985).

[17] O. B. Firsov, Calculation of the interaction potential of atoms, Zh. Eksp. Teor. Fiz., Vol.33, pp.696 (1957)

[18] H. F. Winter, and P. Sigmund, Sputtering of chemisorbed gas (nitrogen on tungsten) by low energy ions, J. Appl. phys. Rev. Appl. phys., Vol.45, no.11 (1974). 


\section{University of Thi-Qar Journal Vol.11 No.2 June 2016}

Web Site: https://jutq.utq.edu.iq/index.php/main Email: journal@jutq.utq.edu.iq

[19] P.Sigmund and P. Vajda, Classical Scattering Cross Sections for Radiation - damage Calculations (Cut off Potentials, pp.25, no.83) and (The - Born Mayer Potential, pp.23, no.84), Danish Atomic Energy Commission Riso Report (1964).

[20] P. Sigmund, Sputtering by ion bombardment: theoretical concepts, Top. Appl. phys.(Springer), Vol.47, pp.9 - 71 (1981).

[21] GL. Chen, Quoted in: J. Bohdansky, A universal relation for the sputtering yield of monatomic solids at normal ion incidence, Nucl. Instr. And Meth., B, Vol.2, pp.587 - 591 (1984).

[22] N. Matsunami, Y. Yamamura, Y. Itikawa, N. Itoh, Y. Kazumata, S. Miyagawa, K. Morita, and R. Shimizu, A semiempirical formula for the energy dependence of the sputtering yield, Rad. Effects Lett., Vol. 57, pp.15 -21 (1980).

[23] M. T. Robinson, "The Physics Of Ion Sputtering", in Oak Ridge National Laboratory, operated by Martin Marietta Energy Systems, Knoxville, TN, USA, (1984).

[24] M. T. Robinson, Sputtering by Particle Bombardment, Top. Appl. phys. (Springer), Vol.47, pp.73 - 144 (1981).

[25] Y. Kudriavtsev, A. Villegas, A. Godines, and R. Asomoza, Calculation of the surface binding energy for ion sputtered particles, Applied Surface Science, Vol. 239, pp.273 - 278 (2005)

[26] A. Tolstogouzov, S. Daolio, C. Pagura, C. L. Greenwood b, D. S. Karpuzov, and N.S. McIntyre, Energy distributions of Ga and In secondary ions sputtered from $\mathrm{A}^{\mathrm{III}} \mathrm{B}^{\mathrm{V}}$ compound semiconductors by noble gas ions: Mass-dependence of the high-energy yield on the second component $(\mathrm{P}, \mathrm{As}$, $\mathrm{Sb}$ ) of the compounds, Nucl. Inst. and Meth., B,Vol.203, pp.198 - 204 (2003).

[27] J.P. Biersack, and W. Eckstein, Sputtering Studies with the Monte Carlo Program TRIM. SP, Appl. Phys., A, Vol.34, pp.73 - 94 (1984). 


\section{الرش المهبطي في المادة الهدف بواسطة الجسيمات المشحونة وطيف الطاقة لذرات الرش الرش

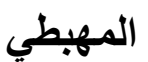

\section{سناء ثامر كاظم (1), سحر مزهر مطشر (2)}

$$
\text { (1) قسم الفيزياء - كلية الطب - جامعة ذي قار }
$$

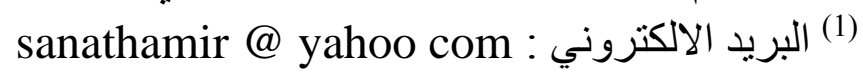

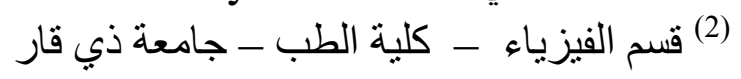

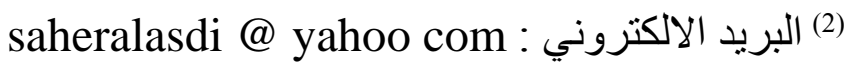

في هذا البحث قدمنا دراسة من اجل توضيح المفهوم الفيزيائي للرش المهبطي للمادة الهدف

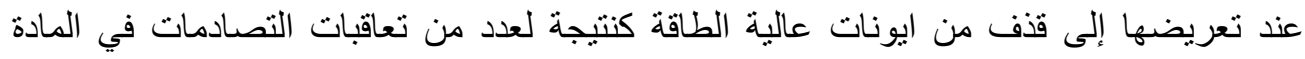

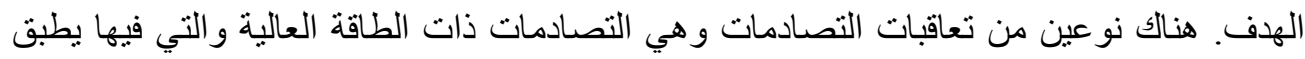

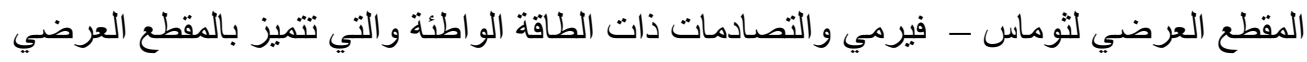

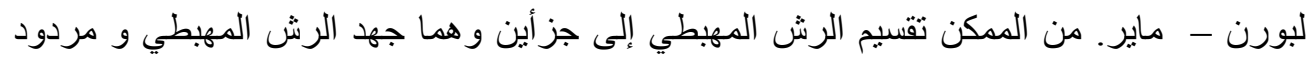

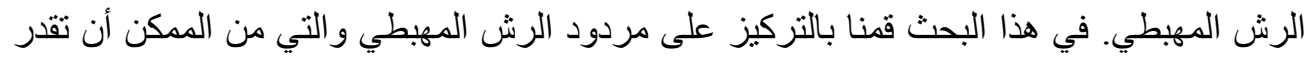

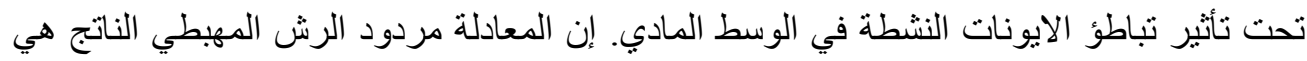

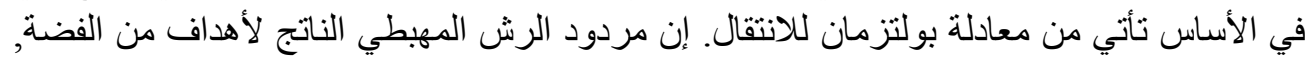

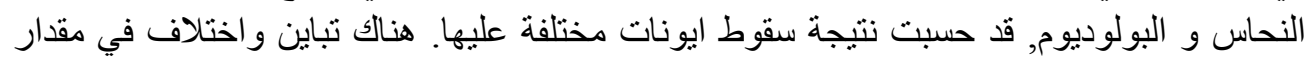

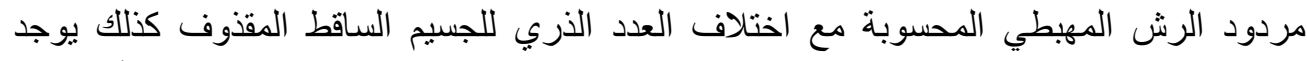
انحر اف في مقدار الطاقة العظمى لكلا النوعين من الجسيمات الساقطة (التقيلة و الخفيفة). أيضا في هذا ابحث تم دراسة صيغة مفترحه من قبل ثومسن لوصف طيف الطاقة للذر ات الملفوظة من المادة

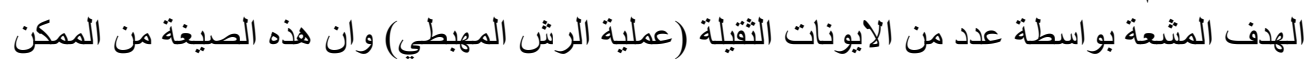

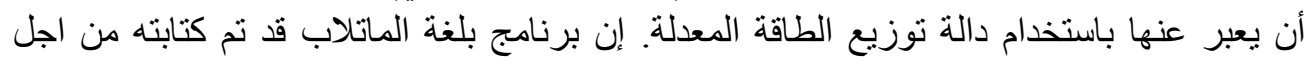
برمجه المعادلات و الحصول على النتائج. 